\title{
Giant Fibroadenoma of Breast mimicking Phylloides Tumour in an Adolescent Girl: Case Report
}

\author{
${ }^{1}$ Dr Manish Kr. Singh, ${ }^{2}$ Dr Alok Kumar, ${ }^{3}$ Dr Prof S. Nag \\ ${ }^{1}$ Asst Prof Surgery, ${ }^{2}$ Asst Prof Surgery, ${ }^{3} \mathrm{HOD}$ \\ Anesthesiology Narayan Medical College Sasaram Bihar
}

\begin{abstract}
We are reporting a rare case of giant fibroadenoma in a 15 year adolescent girl. The provisional diagnosis of the patient was made on FNAC which showed a benign proliferative brest lesion. Total excision of the mass was done preserving nipple and areola. Histopathology features were suggestive of giant fibroadenoma
\end{abstract}

Keywords: Giant fibroadenoma, Adolescent girl, Breast tumor

\section{Introduction:}

Breast development is one of the first obvious signs of puberty. Any variation in its normal progression often deserves attention. Virginal hypertrophy, giant fibroadenoma, and cystosarcoma phylloides are the important differential diagnoses to be considered when one encounters a large breast mass. Although the majority of breast disorders in yong patients are benign, the presence of any breast mass frequently raises parental concerns of a potential cancer( 1,2 ). juvenile or giant fibroadenoma is a rare pathology usually presenting in adolescence characterized by massive and rapid enlargement of the breast. Distinguishing it from cystosarcoma phylloides preoperatively is difficult, but is important as they have a different therapeutic approach and different follow-up 1 ). We report a case of giant fibroadenoma mimicking phylloides tumour of the breast in a 15-year-adolescent girl and discuss the diagnostic possibilities with a review of literature.

\section{Case Report:}

A 15-year-adolescent girl presented with history of rapidly enlarging right breast of six months duration. The mass was painless, and gradually increased to attain the size of approximately $18 \times 17 \mathrm{~cm}$, with no history of trauma, nipple discharge, fever, anorexia, or weight loss. There was no significant family history. On examination, enlargement of the right breast was seen; the left breast was normal. It was a $18 \times 17 \mathrm{~cm}$, solitary, well-circumscribed, firm mass, which was nontender and not adherent to the underlying structures,( Fig.1 ). There was no axillary lymphadenopathy. Systemic examination was normal. Provisional diagnosis of Fibroadenoma of breast was suspected but due to the rapid rate of enlargement and large size, malignant phylloides could not be ruled out. Blood counts were within normal limits. Fine needle aspiration from the mass was suggestive of benign proliferative breast lesion. Total excision of the mass preserving the nipple and areola was done, ( Fig.2,3\&4 ). The cut surface of the lump was tan colored, lobulated with slit-like spaces, with intervening grey white fibrous tissue in between the nodules and focal hemorrhages. Histopathology showed proliferation of stromal connective tissue which surrounded the ductules in a circumferential pattern (pericanalicular type), stroma containing dense fibrous and collagenous tissue admixed with loose fibroblastic tissue. A leaf-like pattern of stroma was also noted. All the features were suggestive of fibroadenoma with benign phyllodes. The girl is being regularly followed up for the last year and is doing well.

\section{Discussion:}

Fibroadenomas are the most commonly (68\%) encountered breast mass in adolescents and are believed to be caused by an abnormal response to estrogen. They typically present as rubbery, discrete, nontender mass, and may be lobular, bilateral (10\%), or multiple (10\% to $15 \%)$.(3). The most common location is the outer upper quadrant of the breast.(4). In adolescent and young adult patients, fibroadenomas are usually not associated with malignancies. The giant fibroadenoma (juvenile cellular fibroadenoma) is an uncommon variant (4\%) of fibroadenoma characterized by rapid growth. Peak incidence occurs in late adolescence, with African-American females at increased risk. The size of the lesion is usually more than $5 \mathrm{~cm}$ but is encapsulated and benign. The underlying mass may cause a major distortion to the breast contour.(5).

Dupont describes two histological groups of fibroadenomas, simple and complex. Complex fibroadenoma refers to fibroadenomas with foci of cysts, sclerosing adenosis, epithelial calcifications, and papillary apocrine metaplasia, and has a higher future risk of malignancy.(6).

The diagnosis of large breast tumors in adolescent females rests primarily on three possibilities: giant fibroadenoma, cystosarcoma phyllodes, and virginal hypertrophy. It is important to distinguish these three 
pathological entities preoperatively as they have different therapeutic approach. Most of the times, physical examination, imaging like ultrasonography of breasts, mammography, and magnetic resonance imaging fail to make diagnosis.(7).

Histologically, giant fibroadenomas have to be differentiated from cystosarcoma phyllodes by the lack of leaf-like structures and stromal cell atypia and from asymmetric breast hypertrophy in girls by the lack of mammary lobules.(8). Other infrequent causes include post-traumatic fat necrosis and mastitis. In fat necrosis of breast, usually a distinct lump need not be palpable while in mastitis all features of inflammation are seen.(9).

Fortunately, majority of these tumors can be completely excised, preserving the nipple and areola, as was done in our patient. Giant juvenile fibroadenoma may recur after complete excision, but the chance of recurrence becomes less after third decade.(10). Although malignant tumors of the breast are rare in the adolescent age group, $2 \%$ of all primary malignant breast lesions occur under the age of 25 years in females.(11).

Marginal excision of the encapsulated tumor which was performed in this case is known to be the standard treatment in fibroadenomas.(12). The clinical significance of different entities is essential as some of the lesions necessitate mastectomy but some lesions may require only local excision, aspiration or even conservative management.

\section{Conclusion:}

Giant fibroadenoma of the breast in a young female is the uncommon condition and a difficult diagnosis on aspiration cytology. In our case diagnosis was mainly established through aspiration cytology in a 15 year adolescent female which subsequently confirmed on histopathology.

\section{References}

1. Dehner LP, Hill DA, Deschryver K. Pathology of the breast in children, adolescents, and young adults. Semin Diagn Pathol 1999 . Aug;16(3):235-247. [PubMed]

2. Foxcroft LM, Evans EB, Hirst C, Hicks BJ. Presentation and diagnosis of adolescent breast disease. Breast 2001. Oct;10(5):399404.10.1054/brst.2001.0292 [PubMed] [Cross Ref]

3. Arca MJ, Caniano DA. Breast disorders in the adolescent patient. Adolesc Med Clin 2004. Oct;15(3):473485.10.1016/j.admecli.2004.06.003 [ubMed] [Cross Ref]

4. West KW, Rescorla FJ, Scherer LR, III, Grosfeld JL. Diagnosis and treatment of symptomatic breast masses in the pediatric population. J Pediatr Surg 1995. Feb;30(2):182-186, discussion 186-187.10.1016/0022-3468(95)90557-X [PubMed] [Cross Ref]

5. Fallat ME, Ignacio RC., Jr Breast disorders in children and adolescents. J Pediatr Adolesc Gynecol 2008. Dec;21(6):311316.10.1016/j.jpag.2007.10.007 [PubMed] [Cross Ref]

6. Dupont WD, Page DL, Parl FF, Vnencak-Jones CL, Plummer WD, Jr, Rados MS, et al. Long-term risk of breast cancer in women with fibroadenoma. N Engl J Med 1994. Jul;331(1):10-15.10.1056/NEJM199407073310103 [PubMed] [Cross Ref]

7. Rattan K, Kumar S, Dhull AK, Kaushal V, Kaur P. Giant Fibroadenoma Mimicking Phyllodes tumor in a Young Female: A Cytological Dilemma. The Internet Journal of Third World Medicine 2008;6:2.

8. Anavi BL, Mishev GG, Ivanov GP. Giant fibroadenoma of the breast. Folia Med (Plovdiv) 2002;44(4):50-52. [PubMed]

9. Ahuja A, Seth A. Juvenile fibroadenoma of breast. Indian Pediatr 2005. Jan;42(1):72. [PubMed]

10. Liang MI, Ramaswamy B, Patterson CC, McKelvey MT, Gordillo G, Nuovo GJ, et al. Giant breast tumors: surgical management of phyllodes tumors, potential for reconstructive surgery and a review of literature. World J Surg Oncol 2008;6:117.10.1186/14777819-6-117 [PMC free article] [PubMed] [Cross Ref]

11. Stehr KG, Lebeau A, Stehr M, Grantzow R. Fibroadenoma of the breast in an 11-year-old girl. Eur J Pediatr Surg 2004. Feb;14(1):56-59.10.1055/s-2004-815782 [PubMed] [Cross Ref]

12. Giant Fibroadenoma of breast in an adolescent Girl. Nithya Thuruthiyath, Purma Chandra Das, etal. Oman Med J. 2012 July; 27 (4): $314-315$.

jnjn

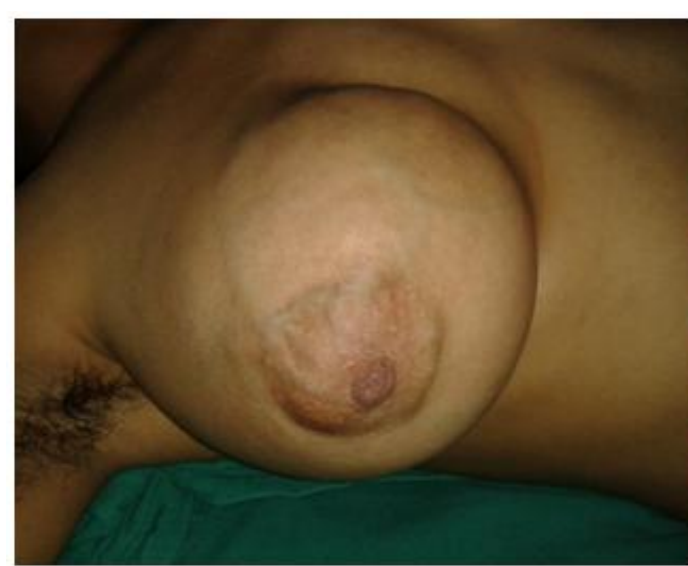

Figure - 1

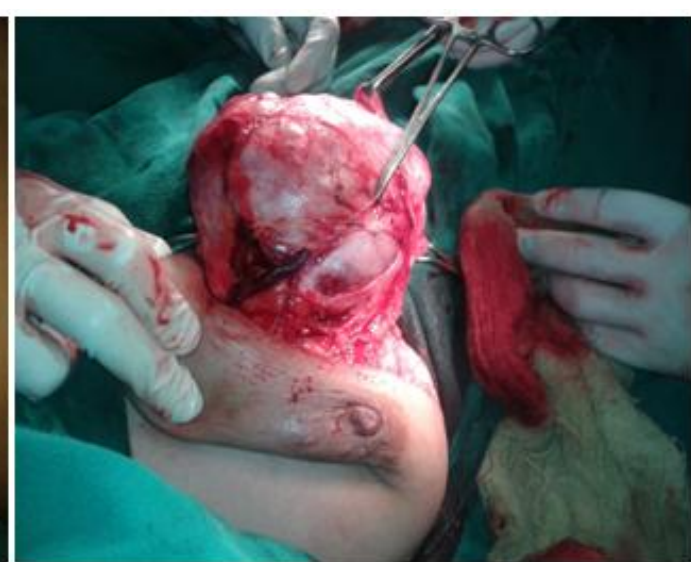

Figure - 2 
Giant Fibroadenoma of Breast mimicking Phylloides Tumour in an Adolescent Girl: Case Report

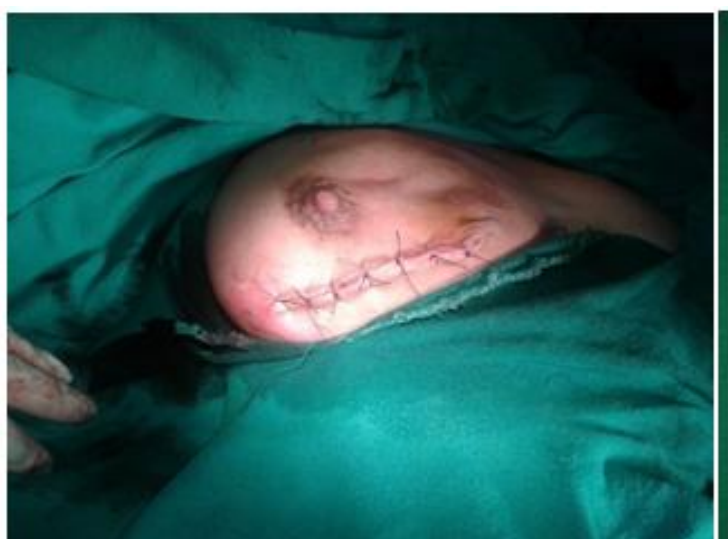

Figure -3

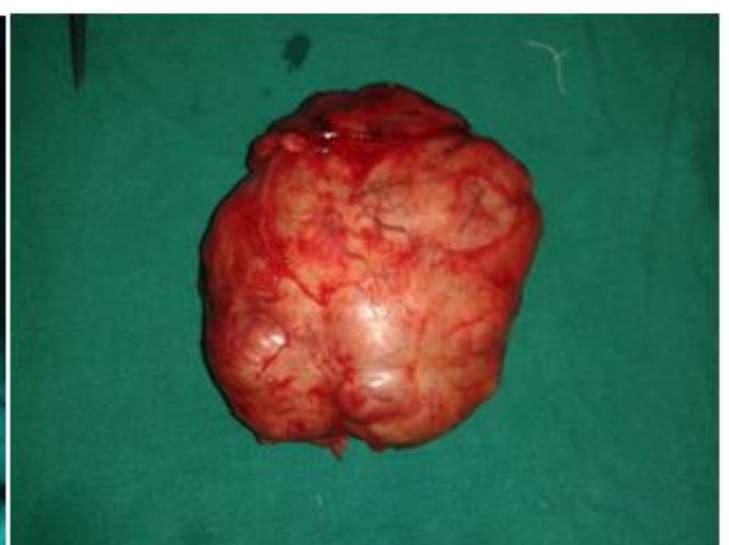

Figure - 4 